\title{
Direitos Humanos na Rede Mercocidades (1995-2015) Uma Temática Transversal?
}

\begin{abstract}
Thiago Felix Mattioli
Doutorando em Ciências Humanas e Sociais na Universidade Federal do ABC. Mestre em Ciências Humanas e Sociais pela Universidade Federal do ABC (2013). Especialista em Filosofia Contemporânea e História pela Universidade Metodista de São Paulo (2011). Bacharel em Relações Internacionais pelo Centro Universitário Fundação Santo André (2009). Tem experiência na área de Ciência Política e Relações Internacionais, com ênfase em Relações Internacionais, Bilaterais e Multilaterais, atuando principalmente nos seguintes temas: Inserção internacional das localidades, Cooperação Descentralizada, Cooperação Internacional para o Desenvolvimento e Cooperação Sul-Sul. http://lattes.cnpq.br/9062162026928225. http://orcid.org/0000-0002-5648-6359. thiago.mattioli@ufabc.edu.br
\end{abstract}

Este artigo discute como o tema de Direitos Humanos pode ser considerado uma temática transversal dentro da Rede Mercocidades. Para tal, é apresentado um breve histórico da Rede Mercocidades e sua estrutura, abordando como os Direitos Humanos podem ser compreendidos a partir de diferentes dimensões, balizados nas codificações internacionais sobre o tema, passando por uma avaliação de como estas dimensões podem ser ligadas a cada uma das unidades temáticas, apontando também a criação de uma comissão específica sobre o tema, que se propõe a promover os Direitos Humanos de forma transversal dentro da Rede.

Palavras-chave: Direitos humanos. Cooperação descentralizada. Mercocidades. Transversalidade.

\section{HUMAN RIGHTS IN THE MERCOCITIES NETWORK (1995-2015): A CROSS-CUTTING THEME?}

\section{ABSTRACT}

This article discusses how Human Rights can be considered as a cross-cutting theme within the Mercocities $\mathrm{Ne}$ twork. To this end, a brief history of Mercocities Network and its structure is presented, addressing how human rights can be understood from its different dimensions, bonded by international encodings on the subject, passing for an assessment of how these dimensions can be connected to each one of the thematic units, also pointing the creation of a special committee on the subject, which aims to promote human rights transversely within the Network.

Keywords: Human rights. Decentralized cooperation. Mercocities. Cross-Cutting.

\section{SUMÁRIO}

1 Direitos humanos: escolas, dimensões e normativas. 2 Rede Mercocidades: criação, institucionalidade e unidades temáticas. 3 Direitos humanos na rede mercocidades: uma temática transversal? 4 Considerações finais. 5 Referências. 


\section{DIREITOS HUMANOS: Escolas, Dimensões e Normativas}

Os Direitos Humanos (DHs), ou os princípios e bases do que se tornariam as normativas atuais sobre o tema, perpassa um grande período de nossa história, podendo ser vista desde a era axial, entre 600 e 480 a.C., até o presente momento (COMPARATO, 2013). Da mesma forma, as discussões teóricas e conceituais também abrangem um grande lapso temporal, com diferentes e distintas formas de interpretação e classificação. Para que seja possível discorrer sobre o tema, em particular em um caso aplicado, entretanto, são necessárias algumas breves considerações sobre o que são os Direitos Humanos, suas escolas de pensamentos e como tais podem ser classificados.

Desse modo, inicia-se esta discussão apresentando sinteticamente as quatro principais escolas de pensamentos identificáveis no campo dos DHs, a saber, a escola naturalista, a escola deliberativa, a escola do dissenso e a escola discursiva. Tais escolas podem ser distinguidas a partir de suas visões sobre como é concebida a existência dos DHs, em que consistem, para quem estão direcionados, quais suas bases, se são realizáveis e se são universais ${ }^{1}$ (DEMBOUR, 2012). As principais características de tais escolas são apresentadas na Tabela a seguir:

Tabela 1 - Escolas de Pensamento em Direitos Humanos: Características Principais

\begin{tabular}{ccccc}
\hline Concepção: & Naturalista & Deliberativa & Dissenso & Discursiva \\
\hline Consiste: & Dados & Acordados & Resultados de lutas & Falados sobre \\
\hline Para: & $\begin{array}{c}\text { Todos os seres huma- } \\
\text { nos }\end{array}$ & $\begin{array}{c}\text { Executar a política de } \\
\text { forma justa }\end{array}$ & $\begin{array}{c}\text { Especialmente para os } \\
\text { que sofrem }\end{array}$ & $\begin{array}{c}\text { Deveriam ser para } \\
\text { os que sofrem }\end{array}$ \\
\hline Baseados: & $\begin{array}{c}\text { Natureza/Deus/Uni- } \\
\text { verso/Razão }\end{array}$ & $\begin{array}{c}\text { Consenso sobre como } \\
\text { a política deve ser } \\
\text { executada }\end{array}$ & Tradição de lutas sociais & Linguagem \\
\hline Realizáveis: & $\begin{array}{c}\text { Sim, por gozo indivi- } \\
\text { dual }\end{array}$ & $\begin{array}{c}\text { Sim, por organização } \\
\text { política }\end{array}$ & $\begin{array}{c}\text { Não, requer luta perma- } \\
\text { nente }\end{array}$ & Não, são falhas \\
\hline Universais: & $\begin{array}{c}\text { Sim, fazem parte da } \\
\text { estrutura do universo }\end{array}$ & $\begin{array}{c}\text { Potencialmente, se o } \\
\text { consenso se espalhar }\end{array}$ & $\begin{array}{c}\text { Sim, pois o sofrimento é } \\
\text { universal }\end{array}$ & $\begin{array}{c}\text { Não, universalidade } \\
\text { é uma pretensão }\end{array}$ \\
\hline
\end{tabular}

Fonte: Adaptada e traduzida de DEMBOUR (2012, p. 144).

No mesmo sentido, os próprios DHs podem ter classificações diferentes a partir da perspectiva adotada pelo pesquisador. As principais formas de classificação são a partir de seu status, de sua geração/dimensão, pelas suas funções e por suas finalidades. A classificação pelo status representa a visão de que os DHs devem ser transformados em leis e normas estatais, para que haja garantias de sua existência e aplicação. Por sua vez, a noção de gerações ou, como se pretende trabalhar neste artigo, dimensões, está baseada no tripé da Liberdade, Igualdade e Fraternidade, oriundos da revolução francesa. A classificação por funções subdivide os DHs entre direitos de defesa, em particular quanto às ações do Estado, direitos a prestações, quando há obrigação do Estado em agir para a efetivação de um DH e os direitos de procedimentos e instituições, que exigem do Estado a organização institucional que ofere-

É importante ressaltar que o modelo proposto por Dembour (2012) não se pretende exaustivo ou estático, uma vez que, mesmo pensadores de uma mesma escola, podem ter visões diferentes sobre tais critérios e temas. 
ce a possibilidade de efetivar tais direitos. Por fim, a classificação por finalidade representa a distinção entre direitos propriamente ditos, as garantias fundamentais que permitem que tais direitos sejam efetivados e a origem de tais normas (RAMOS, 2014).

Considera-se, entretanto, que tais classificações não são necessariamente excludentes, em particular as de gerações e dimensões, funções e finalidades, uma vez que, dentro de tais, seria possível identificar funções e finalidades para cada DH ali elencado. Conforme mencionado, contudo, escolhe-se utilizar aqui o termo dimensões de DH ao invés de gerações, uma vez que, desta forma, podem ser compreendidas como um processo de expansão e acumulação e não de forma limitada como uma sucessão; portanto, ao utilizar tal noção permite-se uma visão integrada destas diferentes dimensões (TRINDADE, 1997).

Desta forma, podem ser identificadas três dimensões distintas, mas relacionadas e relacionáveis, de Direitos Humanos: a primeira refere-se aos direitos ligados aos direitos civis e políticos, a segunda ligada aos direitos sociais, econômicos e culturais e a terceira aos direitos difusos e coletivos (RAMOS, 2014). Entre alguns exemplos, que não se pretendem exaustivos, podem ser considerados como DHs de cada dimensão os apresentados na Tabela 2.

Tabela 2 - Exemplos de Direitos Humanos por Dimensões

\begin{tabular}{cc}
\hline Dimensões & Exemplos \\
\hline 10 Direitos Civis e Políticos & $\begin{array}{l}\text { Direitos à vida, à liberdade, à segurança, à dignidade, à } \\
\text { igualdade, à manifestação, à associação, à privacidade } \\
\text { 20 Direitos Sociais, Econômicos e Culturais } \\
\text { 3o trabalho, à condições de trabalho justas e favorá- } \\
\text { veis, à representação sindical, à saúde, à educação, à } \\
\text { cultura, à ciência, }\end{array}$ \\
\hline $\begin{array}{c}\text { à paz, ao desenvolvimento, à autodeterminação, à } \\
\text { comunicação, ao meio ambiente, à defesa contra a dis- } \\
\text { criminação de minorias }\end{array}$ \\
\hline
\end{tabular}

Fonte: Baseada nos direitos apresentados em OHCR (2017).

Em termos de codificação dos Direitos Humanos, ressalvada toda a questão histórica pertinente ao tema (COMPARATO, 2013), pode-se identificar, como um dos principais marcos contemporâneos, o estabelecimento, em 1948, da Declaração Universal dos Direitos Humanos, reafirmada pela Declaração de Direitos Humanos de Viena em 1993, que, em conjunto com o Pacto Internacional dos Direitos Civis e Políticos e o Pacto Internacional dos Direitos Econômicos, Sociais e Culturais, formam a Carta Internacional dos Direitos Humanos (SALA, 2015).

Deve também ser mencionada a importância e a relevância da Convenção Interamericana de Direitos Humanos (CIDH) de 1969, ${ }^{2}$ parte fundamental do Sistema Regional Interamericano de Proteção dos Direitos Humanos (SIPDH), estabelecendo o entendimento regional sobre esta temática, abordando tanto os direitos civis e políticos quanto os direitos econômicos, sociais e culturais (PIOVESAN, 2014).

\footnotetext{
2 Considerando também o Protocolo de San Salvador, que adiciona à Convenção Interamericana de Direitos Humanos os direitos econômicos, sociais e culturais (PIOVESAN, 2014).
} 
Em termos da recepção da Convenção Interamericana, verifica-se que entre os países da América do Sul apenas a Guiana não assinou ou ratificou a CIDH, e a Venezuela denunciou o tratado em 2012. Desta forma, verifica-se que os países da região, e do Cone Sul em particular, aderem, reconhecem e submentem ao SIPDH (OAS, 2017). Cabe ressaltar, contudo, que o Mercosul não possui uma declaração ou convenção específica sobre o tema de Direitos Humanos.

É importante considerar, porém, que existem as seguintes codificações que se referem aos Direitos Humanos dentro do bloco: Declaração Sócio-laboral do Mercosul, 1998; Carta de Buenos Aires sobre Compromisso Social, 2000; Declaração de Presidentes sobre a Erradicação de Trabalho Infantil, 2002; Acordo sobre a Regularização Migratória Interna de Cidadãos do Mercosul e sobre Residência para Nacionais dos Estados-Parte, 2002; Protocolo de Assunção sobre Compromisso de Promoção e Proteção dos Direitos Humanos no Mercosul, 2005, e Protocolo de Montevidéu sobre o Compromisso com a Democracia no Mercosul (SISTEMA, 2017).

Assim, considerando as definições apresentadas anteriormente e a inserção da região nos sistemas de proteção aos Direitos Humanos, é possível passar para uma breve descrição do objeto deste trabalho: a Rede Mercocidades e como ela se relaciona com temas de DHs.

\section{REDE MERCOCIDADES:}

\section{Criação, Institucionalidade e Unidades Temáticas}

Criada em 1995, a Rede Mercocidades foi fundada pelas cidades de Córdoba, La Plata e Rosário, da Argentina; Brasília, Curitiba, Florianópolis, Porto Alegre, Rio de Janeiro e Salvador, do Brasil; Assunção, do Paraguai; e Montevidéu, do Uruguai. Tendo como objetivo principal a participação desta Rede no processo de integração do Mercado Comum do Sul (Mercosul), em particular em temas de sua competência e interesse, a rede não apenas busca influenciar o processo de integração do bloco, mas também participar de decisões que podem ter impacto direto sobre as cidades integrantes (MERCOCIDADES, 2017d).

A Rede Mercocidades, enquanto parte da estrutura institucional do Mercosul, atuava a partir da criação da Reunião Especializada de Municípios e Intendências do Mercosul (Remi) em 2000, por meio da Resolução 90/00 do Grupo do Mercado Comum. Seu principal objetivo era promover o diálogo e a cooperação entre as cidades dos países do Mercosul, sendo realizadas sete reuniões que tinham como resultados recomendações ao Grupo do Mercado Comum sobre a participação das cidades no processo de integração, acesso ao financiamento e à cooperação internacional, decisões sobre projetos específicos de interesse das localidades, entre outras questões (MERCOSUL, 2000).

Nesta última reunião as cidades sugeriram a revisão desta instância, levando à criação do Fórum Consultivo de Municípios, Estados Federados, Províncias e Departamentos (FCCR) a partir de 2004, entretanto tal Fórum apenas iniciou seus trabalhos em 2007. Seu objetivo é estabelecer um diálogo entre os dirigentes das diversas instâncias subnacionais e seus governos nacionais e a participação no projeto de consolidação do Mercosul, além de agir e fazer recomendações de assuntos de suas competências às instâncias superiores, como o Grupo do Mercado Comum (MERCOCIDADES, 2017b). O FCCR é formado pelo Comitê de Municípios, 


\section{Humanos e}

Democracia

composto pela Rede, e pelo Comitê de Estados, Províncias e Departamentos, cada um com participação de dez membros indicados pelo governo central do Estado Membro, totalizando 20 participantes que, por sua vez, constituem o capítulo do país ${ }^{3}$ (FCCR, 2017).

Em 2017 a Rede possuía 326 cidades membros, sendo 121 argentinas, 9 bolivianas, 87 brasileiras, 20 chilenas, 1 colombiana, 2 equatorianas, 26 paraguaias, 26 peruanas, 20 uruguaias e 14 venezuelanas (MERCOCIDADES, 2017a). ${ }^{4}$ A Rede conta com a seguinte estrutura: Assembleia Geral dos Sócios, órgão máximo de deliberação, Conselho de Mercocidades, órgão superior de administração, Comissão Diretiva, composta pela Presidência, Vice-Presidências, Comissão Diretiva e a Secretaria Executiva que, por sua vez, é a coordenadora dos trabaIhos do Conselho, e a Secretaria Técnica Permanente da Mercocidades (STPM), órgão assessor da Secretaria Executiva (MERCOCIDADES, 2017e).

A Mercocidades também possui Unidades Temáticas (UTs), às quais compete o desenvolvimento de propostas de políticas comuns sobre os temas específicos de cada unidade, a promoção e a divulgação das experiências exitosas e promoção de encontros e eventos para a discussão de problemas locais (MERCOCIDADES, 2017f). Atualmente existem 15 UTs que tratam dos seguintes temas:

Tabela 3 - Unidades Temáticas

\begin{tabular}{|c|c|}
\hline $\begin{array}{l}\text { Unidade } \\
\text { Temática }\end{array}$ & Principais Temas \\
\hline $\begin{array}{l}\text { Ambiente e de- } \\
\text { senvolvimento } \\
\text { sustentável }\end{array}$ & $\begin{array}{l}\text { preservação do solo; biodiversidade; preservação e recuperação dos meios aquáticos; pre- } \\
\text { servação e recuperação dos meios atmosféricos; educação ambiental; gestão de resíduos } \\
\text { sólidos. }\end{array}$ \\
\hline $\begin{array}{l}\text { Autonomia, } \\
\text { gestão e partici- } \\
\text { pação }\end{array}$ & $\begin{array}{l}\text { processos de modernização administrativa; participação cidadã; sistemas jurisdicionais; au- } \\
\text { tonomia e arrecadação municipal. }\end{array}$ \\
\hline $\begin{array}{l}\text { Ciência, } t \\
\text { gia e cap }\end{array}$ & $\begin{array}{l}\text { cooperação científico-tecnológica; premiação de melhor investigação no âmbito da Merco- } \\
\text { cidades. }\end{array}$ \\
\hline $\begin{array}{l}\text { Cooperação in- } \\
\text { ternacional }\end{array}$ & $\begin{array}{l}\text { ações de capacitação e informação sobre temáticas de interesse da rede; criação de um } \\
\text { banco de dados de experiências internacionais positivas; busca de novas ferramentas de } \\
\text { cooperação internacional. }\end{array}$ \\
\hline Cultura & $\begin{array}{l}\text { literatura; música; fotografia; pintura; dança; artes plásticas; cinema; premiação de melhor } \\
\text { projeto cultural em execução. }\end{array}$ \\
\hline $\begin{array}{l}\text { Desenvolvimento } \\
\text { econômico local }\end{array}$ & $\begin{array}{l}\text { identificação de atividades dinâmicas não tradicionais; desenvolvimento da gestão de qua- } \\
\text { lidade; consolidação de uma base de informação econômica e para publicação de expe- } \\
\text { riências de financiamento no âmbito municipal para micros e pequenas empresas; organi- } \\
\text { zação de feiras de negócios. }\end{array}$ \\
\hline $\begin{array}{l}\text { Desenvolvimento } \\
\text { social }\end{array}$ & $\begin{array}{l}\text { novos modelos de gestão de políticas sociais; as dimensões sociais da pobreza; estratégias } \\
\text { políticas de grupos vulneráveis; coordenação interjurisdicional das políticas sociais; elabo- } \\
\text { ração de uma Agenda Social para o Mercosul. }\end{array}$ \\
\hline $\begin{array}{c}\text { Desenvolvimento } \\
\text { urbano }\end{array}$ & $\begin{array}{l}\text { propostas de políticas comuns; investigação de questões da disciplina urbanística; difusão } \\
\text { das experiências que contribuam ao melhoramento das gestões urbanas locais; promoção } \\
\text { de concurso internacional de fotografia urbanística. }\end{array}$ \\
\hline
\end{tabular}

3 O fórum possui o capítulo argentino, o brasileiro, o uruguaio e o venezuelano (FCCR, 2017).

${ }^{4}$ Contabilização feita pelo autor a partir dos dados disponíveis em MERCOCIDADES, 2017a. 


\begin{tabular}{|c|c|}
\hline Educação & $\begin{array}{l}\text { descentralização dos sistemas educativos; consolidação dos novos campos de trabalho; } \\
\text { formação do docente; desenvolver propostas de educação a serem apresentadas aos Mi- } \\
\text { nistérios de Educação. }\end{array}$ \\
\hline $\begin{array}{l}\text { Gênero e muni- } \\
\text { cípio }\end{array}$ & $\begin{array}{l}\text { participação das mulheres no desenho das políticas públicas; eliminar as desigualdades } \\
\text { que limitam os direitos das mulheres; Projeto: Há uma agenda regional das mulheres: Polí- } \\
\text { ticas locais de gênero na Rede Mercocidades. }\end{array}$ \\
\hline $\begin{array}{c}\text { Integraç } \\
\text { teir }\end{array}$ & $\begin{array}{l}\text { medidas para o desenvolvimento das zonas fronteiriças dentro do processo de integração } \\
\text { regional do Mercosul; propostas visando à criação de regiões de cooperação transfronteiri- } \\
\text { ça e de consórcios públicos de fronteira e o debate sobre a necessidade de criar-se legisla- } \\
\text { ções específicas para as zonas fronteiriças dos países do Mercosul. }\end{array}$ \\
\hline Juvent & $\begin{array}{l}\text { reflexão sobre os avanços e dificuldades nos processos de descentralização e integração re- } \\
\text { gional; potencializar a rede de organismos locais de juventude com a finalidade de fomen- } \\
\text { tar o intercâmbio de experiências em políticas locais de juventude e participação juvenil; } \\
\text { comparar mecanismos de funcionamento das Secretarias e Escritórios de juventude com o } \\
\text { objetivo de integrá-las. }\end{array}$ \\
\hline
\end{tabular}

Planejamento estratégico e áreas metropolitanas

identificar práticas exitosas e soluções a problemas comuns; apresentar anualmente delineamento para a concretização dos planos estratégicos das cidades da Rede.

Segurança cidadã

levantar experiências em curso na região; desenvolver um sistema de indicadores; criar um banco de dados sobre melhores práticas; incrementar as capacidades dos governos locais; investigar as possibilidades de financiamento e condições de sustentabilidade de políticas locais em matéria de seguridade cidadã.

revitalização dos centros; artesanato; marketing turístico; turismo religioso; turismo rural;

Turismo qualificação dos recursos humanos; organiza anualmente o prêmio Mercocidades de turismo.

Fonte: Adaptada de DESSOTTI (2011) e atualizado pelo autor com informações de MERCOCIDADES, $2017 f$.

Em termos teórico-conceituais, enquanto compreendida como uma rede internacional de cidades, é possível verificar a aplicação do princípio da horizontalidade, uma vez que não há comando único centralizado na rede, sendo possível a classificar como uma rede territorial, uma vez que agrega cidades pertencentes ao Cone Sul e ao Mercosul, e também uma rede temática, a partir da existência e do desenvolvimento de atividades a partir de unidades temáticas específicas (CARDARELLO; RODRIGUEZ, 2004). O relacionamento entre as cidades se dá por meio da paradiplomacia, compreendida como o estabelecimento de contatos permanentes ou não entre governos não centrais para a discussão ou promoção de questões socioeconômicas, culturais ou ligadas às suas competências (CORNAGO, 1999).

Já a efetivação destes relacionamentos e as atividades desenvolvidas podem ser entendidas como uma forma de cooperação internacional descentralizada, ou seja, uma forma de cooperação que é realizada de maneira multilateral, congregando diferentes atores e com um enfoque das relações de cooperação que busca estabelecer relações diretas com os órgãos de representação local e estimular suas próprias capacidades de projetar e levar a cabo iniciativas de desenvolvimento com a participação direta dos grupos de população interessados, considerando seus interesses e seus pontos de vista sobre o desenvolvimento (HAFTECK, 2003; ROMERO, 2004).

\section{DIREITOS HUMANOS NA REDE MERCOCIDADES: Uma Temática Transversal?}

Como mencionado em seção anterior, não há uma convenção internacional de DHs para o Mercosul. Em 2004, entretanto, foi criada a Reunião de Altas Autoridades em Direitos Humanos e Chancelarias do Mercosul e Estados Associados (RAADH), que trata das discussões e 
promoção de políticas regionais sobre o tema, e, a partir de sua terceira reunião, em 2006, foram dadas as bases de criação de um organismo que, efetivamente criado em 2009, tornou-se o Instituto de Políticas Públicas e Direitos Humanos do Mercosul (IPPDH), ao qual cabe a pesquisa e a produção de estudos técnicos, a difusão e a capacitação do tema e a coordenação de políticas e cooperação em Direitos Humanos (INSTITUTO, 2015). A criação desta reunião e do IPPDH demonstra que os governos reunidos neste bloco se preocupam com questões de DHs e tentam avançar em uma compreensão regional do que estes direitos representam e como podem ser traduzidos em políticas públicas de promoção e efetivação.

A criação destas instituições, todavia, não apresenta como a Rede Mercocidades, que pretende fazer parte do processo de integração regional, atua na temática de DHs. Para que seja verificado como a Rede trata destes temas é necessário, portanto, verificar em cada Unidade Temática se os assuntos abordados estão em consonância com as diferentes dimensões dos Direitos Humanos e podem ser derivados dos códigos internacionais que os tratam.

Para tal, identificaram-se quais UTs, a partir de seus nomes e temas principais, apresentam aderência às dimensões dos DHs expostos na Tabela 2, a partir de seus principais temas, observados na tabela 3. Para confirmar tais aderências, também se verificou, a partir de Dessotti (2011), os encaminhamentos de cada rede temática ${ }^{5}$ na busca de temas de Direitos Humanos, civis, políticos, econômicos, sociais e culturais.

Desta forma, é possível, inicialmente, identificar as seguintes relações entre dimensões e unidades temáticas (Tabela 4).

Tabela 4 - Relações entre Unidades Temáticas e Dimensão de Direitos Humanos

Unidades Temáticas

Dimensão de Direitos Humanos

\begin{tabular}{|c|c|}
\hline Ambiente e desenvolvimento sustentável & 3o Dimensão \\
\hline Autonomia, gestão e participação & 1ㅇ Dimensão \\
\hline Ciência, tecnologia e capacitação & 3o Dimensão \\
\hline Cooperação internacional & 2ㅇ e 3음 Dimensão \\
\hline Cultura & 2o Dimensão \\
\hline Desenvolvimento econômico local & 2o Dimensão \\
\hline Desenvolvimento social & 2o Dimensão \\
\hline Desenvolvimento urbano & 2o Dimensão \\
\hline Educação & 10, 2ㅇ e 3ㅇ Dimensões \\
\hline Gênero e município & 10 e 3음 Dimensões \\
\hline Integração fronteiriça & 10, 2ㅇ e 3ㅇ Dimensões \\
\hline Juventudes & 2ㅇ e 3음 Dimensões \\
\hline Planejamento estratégico e áreas metropolitanas & 2o Dimensão \\
\hline Segurança cidadã & 1으, 2으 e 3음 Dimensões \\
\hline Turismo & 2o Dimensão \\
\hline
\end{tabular}

É necessário mostrar que diversas unidades temáticas não possuem documentações disponíveis desde a data de sua criação, e a verificação foi feita a partir dos documentos apresentados em suas seções do site principal da rede. 
A partir desta primeira relação, é possível identificar que cada unidade temática se aproxima mais de uma determinada dimensão dos Direitos Humanos, considerando que algumas das unidades tratam de temas que perpassam mais de uma dimensão, como no caso UT de educação que trata, ao mesmo tempo, de direitos civis e políticos, direitos econômicos, sociais e culturais, abordando também temáticas de direitos difusos e coletivos. É necessário, entretanto, mencionar que esta aproximação inicial apenas indica uma possibilidade de análise, uma vez que também se verifica que as unidades tratam muito mais dos temas em termos técnicos e de promoção e discussão de políticas do que na definição e defesa dos temas como sendo específicos de Direitos Humanos.

No que diz respeito aos encaminhamentos das unidades temáticas, divididos entre criação de banco de dados, realização de eventos, promoção de acordos e parcerias e projetos comuns, conforme Quadro elaborado por Dessotti (2011), verifica-se também que cada unidade tangencia os temas de cada dimensão de Direitos Humanos, porém sempre com um caráter mais técnico e do diálogo e promoção de políticas públicas.

Um caso que deve ser destacado é a criação de uma Comissão de Direitos Humanos (CDH) em 2006, dentro da UT Desenvolvimento Social. Esta comissão tem como meta trabaIhar em diferentes temáticas, promovendo o respeito às obrigações internacionais de Direitos Humanos em âmbito nacional, estadual e municipal (MERCOCIDADES, 2017g). A partir das avaliações feitas pela Secretaria Técnica Permanente da Mercocidades (STPM), baseada em metodologia própria que considera a existência, qualidade e realização de planos de trabalho, atividades, produtos e participação, apresenta-se a Tabela 5, resumindo a atuação desta comissão durante o período 2009-2015. ${ }^{6}$

Tabela 5 - Avaliação do Grupo de Direitos Humanos: 2009-2015

\begin{tabular}{ccccccc}
\hline Período & Plano de Trabalho & Atividades & Produtos & Participação & Total & Categoria \\
\hline $2009-2010$ & 2 & 2 & 1 & 2 & 7 & Proativo \\
\hline $2010-2011$ & 2 & 2 & 2 & 2 & 8 & Proativo \\
\hline $2011-2012$ & 2 & 2 & 2 & 2 & 8 & Proativo \\
\hline $2012-2013$ & 0 & 2 & 0 & 1 & 3 & Ativo \\
\hline $2013-2014$ & 2 & 1 & 1 & 0 & 4 & Ativo \\
\hline $2014-2015$ & 0 & 1 & 1 & 2 & 4 & Ativo \\
\hline
\end{tabular}

Considerando as dados supra, é possível verificar que a $\mathrm{CDH}$ teve uma atuação que pode ser considerada em dois períodos: 2009-2012 como proativa. Isto é, apresentou planos de trabalhos detalhados com linhas políticas bem-delimitadas; desenvolveu atividades, como encontros, reuniões e workshops durante o período; criou bases de dados, publicações ou boletins e contou com a participação de, pelo menos, seis cidades de três países diferentes do bloco. Em seu segundo período, entre 2012-2015, houve uma pequena queda em suas avalia- 
ções, e isto é visto na falta de planos de trabalhos em 2012-2013 e 2014-2015, além da realização de poucas atividades, poucos produtos e baixa participação neste período, em geral. A soma das notas, entretanto, ainda permitiu que a $\mathrm{CDH}$ fosse considerada ativa.

Os planos de trabalhos disponíveis (2006-2008, 2010-2011, 2014-2015 e 2015-20167) apresentam, de forma mais específica, os planos da CDH. Em geral, discorrem sobre as temáticas que seriam abordadas, como questões de infância, tráfico de pessoas, trabalho escravo, locais de memória, direitos de identidade, discriminação, acesso à justiça, promoção de direitos e políticas públicas relacionadas ao tema de DHs (CDH, 2006, 2010, 2014, 2015).

Em seu plano de trabalho 2010-2011 apresenta seu projeto Direitos Humanos: Estado e sociedade civil, construção de cidadania $(E+D)$, que, realizado em 30 meses, desenvolveu ações na temática de Direitos Humanos e construção de cidadania em mais de 200 cidades (MERCOCIDADES, 2017h). Os informes da STPM, nos quais consta breves exposições sobre as atividades realizadas pelas UTs, apresentam que, durante o período entre 2009-2010, a CDH realizou diversas reuniões, encontros e workshops com suas cidades associadas, sendo alguns destes articulados com outras UTs. Da mesma forma, a comissão encontrou alguns problemas para a realização de suas atividades, em particular a falta de participação de associadas e a dificuldade de comunicação e continuidade de projetos, dadas as alterações políticas ocorridas em suas cidades associadas (MERCOCIDADADES, 2017b).

Quanto às atas da $\mathrm{CDH}$, ressalta-se também que as discussões representadas nas atas apontam para a transversalidade do tema de Direitos Humanos e a necessidade de esta comissão manter e aprofundar suas relações com as demais unidades, de forma a promover, de maneira efetiva, o tema de Direitos Humanos dentro da Rede (MERCOCIDADES, 2017h).

\section{CONSIDERAÇÕES FINAIS}

A questão dos Direitos Humanos, em particular sobre sua proteção e promoção, tem sido desenvolvida em um sentido histórico, ganhando contornos mais bem delineados a partir das codificações internacionais sobre o tema, em particular no pós-Segunda Guerra Mundial. Na esteira das codificações internacionais feitas no seio do Sistema da Organização das Nações Unidas, os diferentes sistemas regionais e sub-regionais iniciaram seus próprios processos de codificação, apresentando inovações de Direitos Humanos, plasmando em seus textos dimensões mais largas e assegurando sua promoção e proteção.

A temática de Direitos Humanos, entretanto, não pode ser compreendida apenas como um assunto de alta política ou um tema inacessível. $O$ direito humano também é um direito do indivíduo e de sua comunidade, portanto um direito que deve ser respeitado e exercido localmente. É a partir desta preocupação com o local que nasce a questão que norteia este artigo: "Como os Direitos Humanos são tratados em uma rede internacional de cidades sulamericanas?" Com o intuito de responder a tal questão, foi apresentada uma breve descrição do que é e de como se estrutura a Rede Mercocidades e, de forma mais específica, como esta rede trata esta temática.

Neste caso é possível notar que, apesar da existência e boa avaliação dos planos de trabalho no período, o site da Rede Mercocidades não possui todos estes planos disponíveis para download. 
Foi possível verificar, mesmo que de forma ainda inicial, uma grande ligação entre as unidades temáticas específicas, quando os diferentes temas acabam por se relacionar com a promoção e a proteção de direitos civis, políticos, econômicos, sociais, culturais, difusos e coletivos, mesmo que tais direitos estejam tangenciados em discussões mais técnicas e de promoção de políticas públicas. Foi possível, ainda, verificar, de forma particular, a criação de uma comissão específica para discutir os Direitos Humanos dentro da Rede, com projetos de promoção deste tema e com uma visão que abarca o relacionamento desta comissão e das diferentes unidades temáticas.

Desta forma, é possível afirmar que o tema de Direitos Humanos é, sim, um tema transversal dentro da Rede Mercocidades, uma vez que ele aparece nas diferentes unidades específicas, mas também vem sendo promovido - de forma transversal - por uma comissão que busca inserir a temática de maneira mais aprofundada e com a proposta de projetos específicos em cada unidade temática.

\section{REFERÊNCIAS}

CARDARELLO, A.; RODRIGUEZ, J. Networks of cities as a privileged tool for decentralised co-operation management. Decentralized Cooperation Observatory, 2007. Available from: http://observ-ocd.org/sites/observ-ocd. org/files/publicacion/docs/299_134.pdf. Cited: 22 abr. 2015.

COMPARATO, F. K. A afirmação histórica dos Direitos Humanos. São Paulo: Saraiva, 2013.

CORNAGO, N. Diplomacy and paradiplomacy in the redefinition of international security: dimensions of conflict and co-operation. In: ALDECOA, F.; KEATING, M. Paradiplomacy in action: the foreign relations of subnational governments. Portland: Frank Cass, 1999. p. 40-57.

DEMBOUR, Marie-bénédicte. What are human rights?: Four schools of thought. In: CUSHMAN, Thomas. Handbook of human rights. New York: Routledge, 2012. p. 137-145.

DESSOTTI, F. R. Rede Mercocidades na cooperação descentralizada: limites e potencialidades. São Paulo: PUC-SP, 2011.

FCCR. Fórum Consultivo de Municípios, Estados Federados, Províncias e Departamentos do Mercosul, 2017. Disponível em: http://www4.planalto.gov.br/saf-fccr/fccr-mercosul/estrutura. Acesso em: 22 set. 2017.

HAFTECK, P. An introduction to decentralized cooperation: definitions, origins and conceptual mapping. Public administration and development, v. 23, p. 333-345, jul. 2003.

INSTITUTO de Políticas Públicas e Direitos Humanos do Mercosul. 2015. Disponível em: http://www.ippdh.mercosur.int/?lang=pt-br. Acesso em: 4 dez. 2015.

MERCOCIDADES. Cidades Membros. 2017a. Disponível em: http://www.mercociudades.org/node/2352. Acesso em: 11 set. 2017.

MERCOCIDADES. Descripción del FCCR. Mercociudades. 2017b. Disponible en: http://www.mercociudades.org/ node/2288. Acceso en: 5 set. 2017.

MERCOCIDADES. Documentos y Archivos. 2017c. Disponible en: http://www.mercociudades.org/node/2100. Acceso em: 12 ago. 2017.

MERCOCIDADES. Declaração de Assunção. 2017d. Disponível em: http://www.mercociudades.org/sites/portal. mercociudades.net/files/archivos/documentos/DocumentosFundacionales/1995actafundacional1.pdf. Acesso em: 11 set. 2017.

MERCOCIDADES. Estatuto Social. 2017e. Disponível em: http://www.mercociudades.org/sites/portal.mercociudades.net/files/archivos/documentos/Estatutos/ESTATUTO.pdf. Acesso em: 11 set. 2017.

MERCOCIDADES. Unidades Temáticas. 2015f. Disponível em: http://www.mercociudades.org/pt-br/node/2287. Acesso em: 11 set. 2017.

MERCOCIDADES. Unidades Temáticas. Desenvolvimento Social; Comissão de Direitos Humanos. 2017g. Disponível em: http://www.mercociudades.org/pt-br/node/2217. Acesso em: 11 set. 2017

MERCOCIDADES. Unidades Temáticas. Desenvolvimento Social; Comissão de Direitos Humanos. Documentos. 2017h. Disponível em: http://www.mercociudades.org/pt-br/node/4455. Acesso em: 11 set. 2017 
MERCOSUL. Resolução 90/00. Mercosul. 2000. Disponível em: http://gd.mercosur.int/SAM/GestDoc/ pubweb.nsf/OpenFile?OpenAgent\&base=SAM/GestDoc/DocOficOArch.nsf\&id=832579C700726F0D032576B300527D15\&archivo=RES_090-2000_PT_ReuMunilntende.pdf. Acesso em: 11 set. 2017.

OHCR. Office of the High Comissioner on Human Rights. International bill of Human Rights. 2017. Available from: http://www.ohchr.org/Documents/Publications/Compilation1.1en.pdf. Cited: 11 set. 2017.

OAS. Organização dos Estados Americanos. Convención Americana sobre Derechos Humanos: Firmas. 2017. Disponible en: http://www.oas.org/dil/esp/tratados_B-32_Convencion_Americana_sobre_Derechos_Humanos_firmas.htm. Acceso en: 11 set. 2017.

PIOVESAN. F. Direitos Humanos e Justiça Internacional. 5. ed. São Paulo: Saraiva, 2014.

RAMOS, André de Carvalho. Curso de direitos humanos. São Paulo: Saraiva, 2014.

ROMERO, M. D. H. Una aproximación contextual y conceptual a la cooperación decentralizada. Valparaíso e Barcelona: Dencetralized Cooperation Observatory, 2004.

SALA, J. B. Sistemas de proteção internacional dos Direitos Humanos. [S./I.]: [s./n.]. 2015. Disponível em: https:// dhmrufabc.files.wordpress.com/2015/10/sistemas-de-protec3a7c3a3o-internacional-dos-direitos-humanos.pdf. Acesso em: 4 dez. 2015.

SISTEMA de Informações sobre Institucionalidade em Direitos Humanos do Mercosul. Instituto de Políticas Públicas e Direitos Humanos. Disponível em: http://sisur.ippdh.mercosur.int/si/web/pt/ficha/mercosur. Acesso em: 11 set. 2017.

TRINDADE, A. A. C. Tratado de direito internacional dos direitos humanos. Porto Alegre: Sérgio Antonio Fabris, 1997. Vol. 1. 